
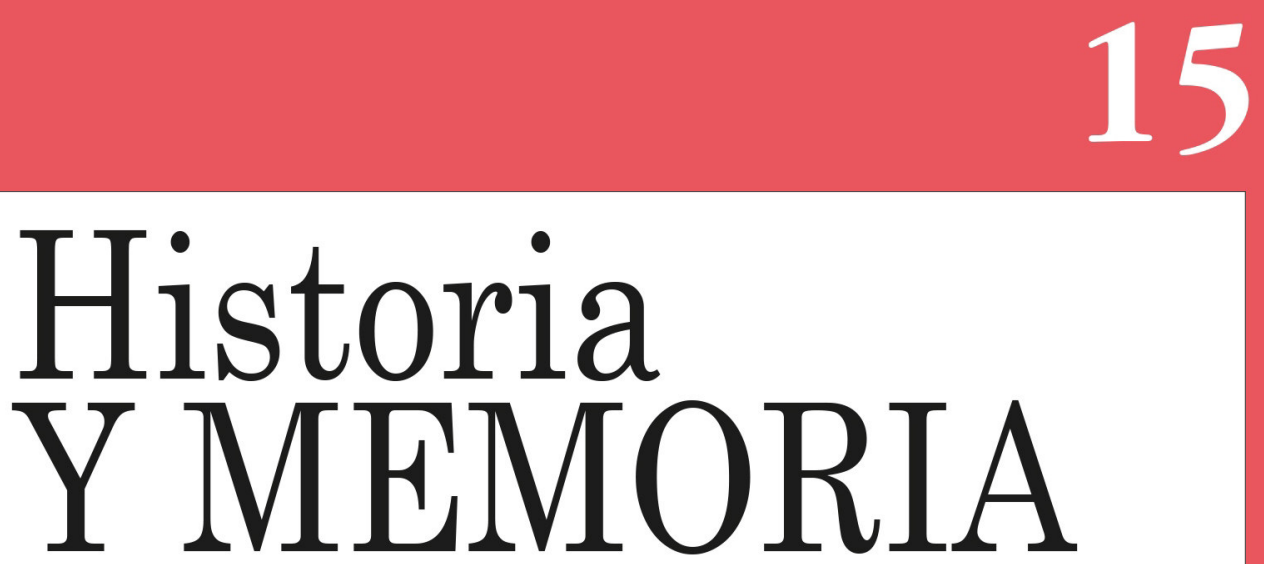

ISSN: 2027-5137 Julio - Diciembre, Año 2017 - Tunja, Colombia

El museo arqueológico de Pasca: una hipótesis sobre su origen

https://doi.org/10.19053/20275137.n15.2017.5511

José Abelardo Díaz Jaramillo

orcid.org/0000-0001-8279-2379

Páginas: 17-48

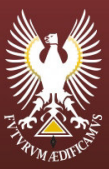




\title{
El museo arqueológico de Pasca: una hipótesis sobre su origen
}

\author{
José Abelardo Díaz Jaramillo ${ }^{1}$ \\ Corporación Universitaria del Meta - Colombia
}

Recepción: 26/10/2016

Evaluación: 09/03/2017

Aprobación: 21/04/2017

Artículo de Investigación e Innovación.

https://doi.org/10.19053/20275137.n15.2017.5511

\section{Resumen}

El artículo indaga por el origen del Museo Arqueológico de Pasca (MAP). Se argumenta que su creación respondió a una estrategia sociocultural diseñada por el párroco Jaime Hincapié Santamaría, para fortalecer los vínculos entre la comunidad y la parroquia, en un contexto local marcado por conflictos agrarios, los cuales configuraron, en un proceso de larga duración, una base política afín a las ideas liberales y comunistas entre sus pobladores. Lo singular del interés que acompañó la iniciativa del párroco, como se intentará demostrar, es que no estuvo matizado por un discurso religioso, sino por la reivindicación domesticada del pasado indígena local. Para tal fin, se acude a una estrategia que articula conocimientos de orden histórico sobre el contexto local en que surgió el MAP, y sobre la vida del párroco Jaime Hincapié Santamaría, con testimonios de habitantes del municipio que

\footnotetext{
* Artículo derivado de la investigación «Sumapaz: ensayos de historia regional», financiada por la Corporación Universitaria del Meta, la cual inició en 2016 y finalizará en 2017. [El autor expresa agradecimientos a la Licenciada Ángela Camargo Suárez, por su colaboración en la búsqueda de información para la presente investigación]. 1 Magíster en Historia (UNAL); estudiante de doctorado en Historia (UNAL); docente de la Corporación Universitaria del Meta, vinculado al Centro de Investigaciones Socio-jurídicas Jorge Eliécer Gaitán. Líneas de investigación: movimientos estudiantiles, historia de las izquierdas, historia regional y local. Publicaciones recientes: "Anticomunismo y defensa del catolicismo en las protestas estudiantiles en Colombia (1945)», Historia Caribe 12, n 30 (2017): 145-177. jodiz16@yahoo.com (iD) orcid.org/0000-0001-8279-2379
} 
permitieron identificar los significados otorgados al museo. De tal modo, el ejercicio permitirá historiar un lugar de memoria de Sumapaz y resaltar el papel de los curas de pueblo como agentes socioculturales.

Palabras clave: Museo Arqueológico de Pasca, conflictos agrarios, política, hegemonía religiosa.

\section{The Archeological Museum of Pasca: a Hypothesis about its Origin}

\section{Summary}

This article inquires into the origin of the Archeological Museum of Pasca (MAP), argumenting that its creation responds to a sociocultural strategy designed by the parish priest Jaime Hincapié Santamaría in order to strengthen relations between the community and the parish. This took place in a local context marked by agrarian conflicts, which, by means of a long process, configured a political foundation of liberal and communist ideas among its inhabitants. What is singular about this parish priest's interest, as this article aims to demonstrate, is that this effort was not accompanied by religious discourse, but by a domesticated revindication of the indigenous local past. For this purpose, this article uses a strategy that articulates historical knowledge on the local context in which MAP emerged and on the life of Jaime Hincapié Santamaría, with testimonies of the inhabitants of the municipality, which allowed identification of the meanings given to this museum. In this way, this exercise will allow the historization of a place of memory of the Sumapaz region of Colombia, highlighting the role of priests as sociocultural agents.

Key Words: Archeological Museum of Pasca, Agrarian Conflicts, Politics, Religious Hegemony. 


\section{Le musée archéologique de Pasca: une hypothèse à propos de ses origines}

\section{Résumé}

Cet article cherche à connaître les origines du Musée Archéologique de Pasca (MAP). On y explique sa création comme faisant partie d'une stratégie socio-culturelle conçue par le curé Jaime Hincapié Santamaría, afin de renforcer les liens entre la communauté et la paroisse, dans un contexte local marqué par les conflits agraires. Ces conflits, en outre, devaient permettre, dans un processus de longue durée, la configuration d'une base politique proche des idées libérales et communistes des habitants de la paroisse. Ce qui est frappant dans l'initiative du curé c'est quelle n'a pas été nuancée par un discours religieux, mais par la revendication domptée du passé indigène local. Notre stratégie allie des connaissances d'ordre historique, tant à propos du contexte local dans lequel a surgi le MAP que de la vie du prêtre Jaime Hincapié Santamaría, avec des témoignages des habitants de la municipalité qui ont permis d'identifier les significations que l'on prête au musée. Ainsi, l'exercice permettra de faire l'histoire d'un lieu de mémoire du Sumapaz et de souligner le rôle des curés villageois comme agents socio-culturels.

Mots-clés: Musée Archéologique de Pasca, conflits agraires, politique, hégémonie religieuse.

\section{Introducción}

«Un museo dice tanto o más de la sociedad que lo diseña, que de los periodos o temas que pretende exhibir» ${ }^{2}$

«Así, lo que empezó como un museíto doméstico, en un solar contiguo a la iglesia de Nuestra Señora de la Encarnación en Pasca, es hoy el único museo arqueológico de Cundinamarca» ${ }^{3}$

2 Carl Henrik Langebaek Rueda, «Patrimonio arqueológico e investigación en el nuevo Museo Nacional de Colombia» en La arqueología, la etnografía, la historia y el arte en el Museo (Bogotá: Ministerio de Cultura - Museo Nacional de Colombia, 2011), 89.

3 «El de Pasca: un museo con sotana», El Tiempo, Bogotá, 23 de mayo de 1994. 
«Un museo con pueblo». Así, escuetamente, suelen definir a Pasca las personas que, procedentes de otros lugares, visitan el MAP. Para comprender el alcance de la expresión, es necesario haber estado allí; al hacerlo, llama la atención constatar que una pequeña localidad andina alberga un museo arqueológico que se ha convertido en un referente identitario en Sumapaz. Valga decir que de los diez municipios que forman la región, Pasca, uno de los más pequeños, posee un museo historico ${ }^{4}$, algo de lo que carece Fusagasugá, el principal centro urbano de Sumapaz desde los tiempos de la Colonia.

Para entender la existencia del MAP, se debe ahondar la mirada en el contexto histórico en el que se creó, e indagar en la biografía de quien concibió y promovió la idea con inusitado interés. En ese propósito, aquí se establece como hipótesis que el origen del MAP expresó las tensiones sociales de una localidad en una época convulsa, marcada por prolongados conflictos políticos y agrarios, resaltando que la razón de la existencia del MAP fue más allá del interés del párroco Hincapié Santamaría por la preservación de los vestigios de un pasado indígena. Se sostendrá que la construcción de la edificación formó parte de una estrategia sociocultural que buscó trasladar en el tiempo a los pobladores de Pasca, con el fin de sustraerlos de las influencias de la izquierda política. Si bien esa ida hacia tras guardaba relación con el interés del párroco Jaime Hincapié Santamaría por el pasado, se mostrará que en él se conjugaron pretensiones no solo intelectuales (afición por la historia), sino también propósitos ligados a los deberes que le imponía la institución religiosa a la que estaba vinculado y que apuntaban a fortalecer su hegemonía. Para argumentar esta interpretación, se toma en cuenta el planteamiento del antropólogo Cristóbal Gnecco sobre la «domesticación arqueológica de la memoria social»,

4 Álvaro Cárdenas (Docente), entrevista por José Abelardo Díaz Jaramillo, Fusagasugá, mayo de 2011. En una nota de prensa sobre el MAP, se lee que los viajeros desprevenidos «no se imaginan que en una población que no supera las cuatro calles y seis carreras y los 12.000 habitantes, exista un museo de su valor cultural e histórico» y que sea "reconocido en el exterior, pero no en Colombia». («El de Pasca, un museo con Sotana», El Tiempo, Bogotá, 23 de mayo de 1994). 
la cual descansa, en buena parte, en su objetivación espacial, siendo el museo el lugar apropiado para ello ${ }^{5}$.

En ese orden de ideas, el artículo está dividido en cuatro partes: en la primera se describe el contexto social de Pasca desde comienzos del siglo XX, hasta el momento en que el párroco Jaime Hincapié Santamaría arribó a Pasca, a finales de los años cincuenta, resaltando los conflictos agrarios y la presencia de líderes como Erasmo Valencia, Jorge Eliécer Gaitán y Juan de la Cruz Varela, así como el surgimiento de una memoria social articulada a ese pasado; en la segunda parte se reconstruye la vida del padre Hincapié Santamaría, mostrando el sentido social que otorgó a su ejercicio sacerdotal y la relación que entabló con el líder comunista Juan de la Cruz Varela; en la tercera parte, se analizan las estrategias socioculturales desplegadas por el padre Hincapié Santamaría en Pasca, centrando la atención en el MAP y en las circunstancias que rodearon el descubrimiento de la famosa Balsa de Oro; en la parte final, se establecen algunas conclusiones.

\section{Contexto histórico}

Para comprender el contexto que dio origen al MAP, es necesario identificar los antecedentes políticos que se registraron en Pasca en la primera mitad del siglo XX. En el siguiente apartado se hará una breve reconstrucción de la historia local con el fin de resaltar la modificación del mapa político que se operó en esa localidad, fenómeno que estuvo articulado a las tensiones sociales derivadas de la lucha por la tierra. Se sostendrá que la existencia de una afinidad comunista al momento de arribar el párroco Jaime Santamaría a Pasca, solo es comprensible si esta se inscribe en un marco temporal de

$5 \quad$ Cristóbal Gnecco, «Observaciones sobre arqueología, objetos y museos», en $L a$ arqueología, la etnografía, la historia y el arte en el Museo (Bogotá: Ministerio de Cultura - Museo Nacional de Colombia, 2010), 74. Sostiene Gnecco que el museo se convirtió en un dispositivo de poder que enseñó a los ciudadanos lo que deberían recordar, y la forma de hacerlo, «impidiendo la dispersión de la memoria social y cortando de raíz cualquier otra posibilidad de construcción histórica». De tal modo, se construyó una identidad derivada de la idea de un pasado común imaginado, que fue posible a través de la domesticación de la memoria social. 
mayor amplitud, que en el artículo se rastrea desde la década de los años veinte.

\subsection{Pasca en la primera mitad del siglo XX}

Pasca se encuentra ubicado en la provincia de Sumapaz, a dos horas (aprox.) de Bogotá. Habitado en épocas prehispánicas por los muiscas (su nombre es de origen chibcha y significa "cercado del padre»), fue fundado a la manera española en $1537^{6}$. Tiempo después, en 1595, las autoridades constituyeron allí un resguardo de indios, de 14.949 fanegadas, intervenido posteriormente por el alcalde provincial de Bogotá en 1836, lo que dio inicio a un álgido proceso de disputa que derivó en la creación de las haciendas El Retiro y La Constancia ${ }^{7}$. (Ver mapa).

En la segunda década del siglo XX se registraron en la localidad conflictos agrarios que configuraron, con el paso del tiempo, una nueva realidad sociopolítica. Las tensiones surgieron a raíz de la existencia de una estructura agraria basada en una excesiva concentración de tierras en pocas familias, a la par que numerosas personas, careciendo de ellas, oficiaban como arrendatarios y peones al interior de las haciendas. Según un estudio sobre la región de Sumapaz, las protestas agrarias -que datan de 1929- fueron, en parte, derivación de los reclamos de arrendatarios de las haciendas de Fusagasugá, quienes adelantaron sonadas movilizaciones para demandar su derecho a ser propietarios. Entre 1930 y 1934 las protestas se extendieron a Pasca ${ }^{8}$.

6 Roberto Velandia, Enciclopedia histórica de Cundinamarca (Bogotá: Biblioteca de Autores Cundinamarqueses, 1979); Ezequiel Uricoechea, Memoria sobre las antigüedades neo-granadinas (Bogotá: Biblioteca Banco Popular, 1971).

$7 \quad$ Rocío Londoño, Juan de la Cruz Varela. Sociedad y política en la región de Sumapaz (1902-1984) (Bogotá: Universidad Nacional de Colombia, 2011), 233.

8 Londoño, Juan de la Cruz Varela..., 234. 


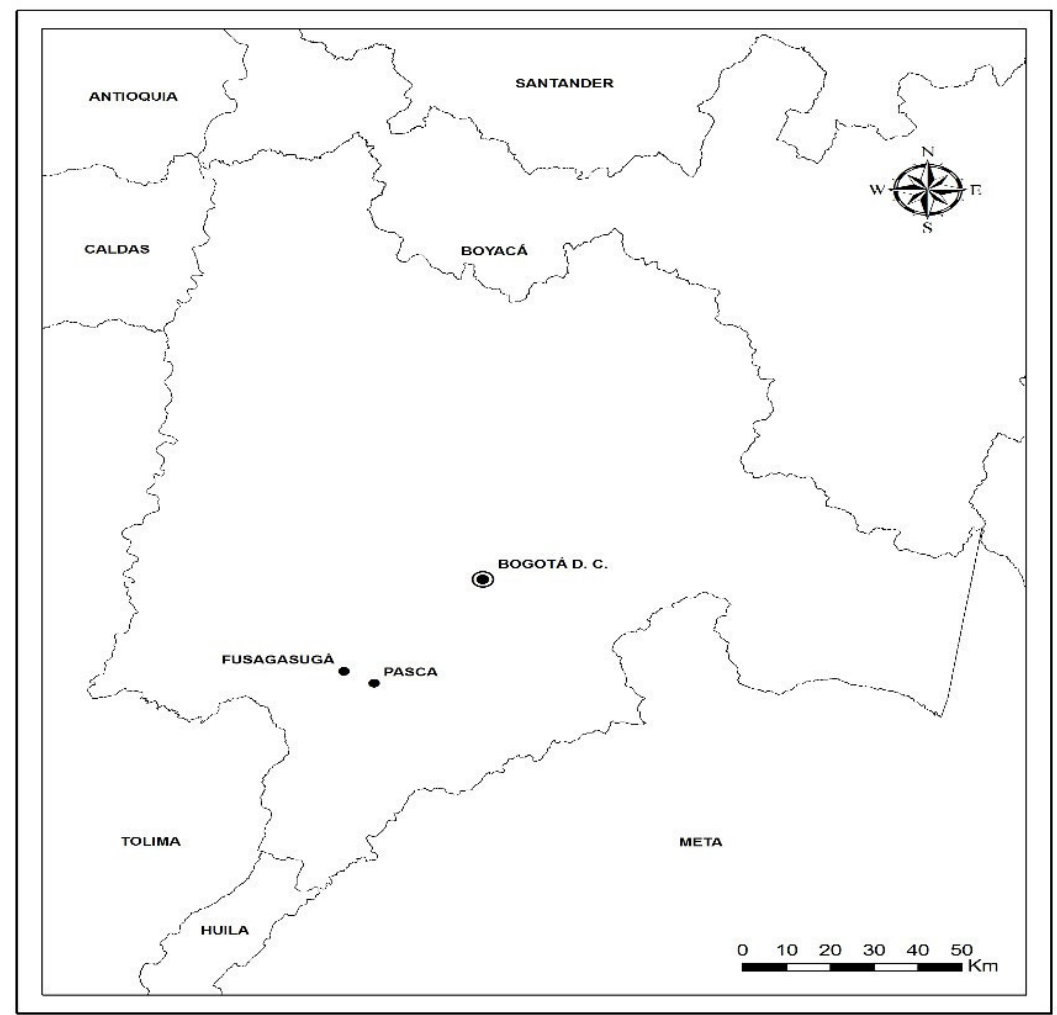

Mapa 1. Ubicación de Pasca (Cundinamarca).

Fuente: Elaboración del autor, con base en mapa de Google Earth.

Como lo muestra la historiografía sobre los conflictos agrarios en Sumapaz ${ }^{9}$, los colonos y arrendatarios recibieron apoyo decisivo de líderes que asumieron la defensa de sus intereses y los dotaron de estrategias organizativas. Un ejemplo lo encontramos en Erasmo Valencia, un periodista de tendencia socialista que prestó asesoría jurídica -sin ser abogado en propiedad- a colonos y aparceros, y los alentó

$9 \quad$ Existe una valiosa bibliografía sobre los conflictos agrarios en Sumapaz, de la que se destacan algunos trabajos: Catherine Legrand, Colonización y protesta campesina en Colombia 1850-1950, (Bogotá: Universidad Nacional de Colombia, 1988); Marco Palacios, El café en Colombia (1850-1970): una historia económica, social y política (México: Fondo de Cultura Económica, 2009); Renán Vega Cantor, Gente muy rebelde. Indígenas, campesinos y protestas agrarias (Bogotá: Pensamiento Crítico, 2002); Londoño, Juan de la Cruz Varela...; Elsy Marulanda, Colonización y conflicto. Las lecciones del Sumapaz (Bogotá: Tercer Mundo Editores, 1981). 
a realizar ocupaciones de tierras y a demandar la revisión de los títulos de propiedad que acreditaban los dueños de las haciendas. Además, Valencia los motivó a constituir organismos para fortalecer las reivindicaciones, como ocurrió con la Sociedad Agrícola de la Colonia de Sumapaz, que tuvo presencia en varios municipios de la región ${ }^{10}$.

La presencia de Erasmo Valencia y la recepción que hicieron los labriegos de sus ideas, fortaleció la creación en 1933 del Partido Agrario Nacional (PAN), que pretendió orientar la inconformidad rural y disputar al bipartidismo las representaciones en las corporaciones locales, como ocurrió en Pasca, donde el nuevo partido obtuvo un sobresaliente apoyo electoral ${ }^{11}$. Además de Erasmo Valencia, Jorge Eliécer Gaitán incidió en los campesinos de Pasca (y del Sumapaz), desde los tiempos de la Unión Nacionalista de Izquierda Revolucionaria (UNIR), movimiento que incluyó en su plataforma política reivindicaciones agrarias, lo que granjeó la simpatía de colonos y arrendatarios de la región ${ }^{12}$. Constituida la UNIR en 1933, no tuvo que pasar mucho tiempo para que Sumapaz se convirtiera en uno de sus principales bastiones electorales. En las elecciones para concejo, en octubre de 1933, la UNIR obtuvo en Pasca un destacado resultado: de los 951 votos que se depositaron, 324 (34\%) fueron para Gaitán, mientras que los liberales obtuvieron $171(18 \%)$ y los conservadores 456 $(48 \%)^{13}$.

Las sorpresas electorales en Pasca continuaron entre 1939 y 1949. La más destacada fue la obtenida por los comunistas en 1939 (43\% de los votos). En la campaña presidencial de 1946,

10 En Pasca existió una sección de la Sociedad Agrícola de la Colonia de Sumapaz, señalada por los hacendarios de promover ideas subversivas entre los campesinos de la región.

11 Gerardo González, En busca del horizonte (Bogotá: Alekos Publicaciones, 1996), 87.

12 J. Cordell Robinson, El movimiento gaitanista en Colombia 1930-1948 (Bogotá: Ediciones Tercer Mundo, 1976).

13 En las elecciones de 1935 el PAN obtuvo ocho concejales en Sumapaz, y superó al liberalismo y el conservatismo en Pasca. Un resultado a todas luces destacado desde una perspectiva regional. Ver Londoño, Juan de la Cruz Varela..., 346. 
el candidato Gaitán se impuso en Sumapaz sobre el candidato conservador y sobre Gabriel Turbay, el otro candidato liberal, obteniendo una amplia mayoría en varios municipios, entre ellos, Pasca, cuya población era, junto a los arrendatarios de El Chocho (ubicada en Fusagasugá), los militantes más radicales del gaitanismo ${ }^{14}$.

\subsection{La presencia comunista}

Como ocurrió en otros lugares del país, el asesinato de Jorge Eliécer Gaitán en 1948, conmocionó a la región de Sumapaz, y en particular, a Fusagasugá y Pasca. A pocas horas de haberse conocido el trágico suceso, se formaron en las dos localidades juntas revolucionarias que tuvieron el control político durante algunos días. Gerardo González, líder agrario de Pasca, recuerda lo ocurrido allí:

El 9 de abril hay una parálisis total. En Pasca se levantó la gente; del Partido Conservador había muy pocos, la mayoría era liberal, colonos fundamentalmente y amigos de los colonos. Entonces se une más que todo la gente agrarista y se toma la autoridad del gobierno municipal. Un tal primitivo Díaz, que había sido asesor de los colonos, un abogado de esos que llaman tinterillos y que no era graduado pero sabía mucho de Derecho Civil y de memoriales, fue nombrado alcalde provisional. Al tercer día, una familia que herraba bestias y hacia fraguas en carbón mineral tenía varillas y con el fuego hicieron puntas y bastones, y la gente sacó las escopetas que tenían en sus casas. Luego llegó un señor que había estado en la Guerra de los Mil Díaz, medio pariente mío, que se llamaba Miguel Mora, también medio tinterillo, y que era muy famoso, y entonces a él lo nombraron jefe civil y militar de Pasca $^{15}$.

Estos hechos dieron origen a una reacción del conservatismo que se expresó en la persecución a los liberales y comunistas, lo que a su vez motivó la conformación de núcleos armados integrados por las familias perseguidas

14 Londoño, Juan de la Cruz Varela..., 377.

15 Londoño, Juan de la Cruz Varela..., 439. Gerardo González fue un destacado líder agrario oriundo de Pasca y militante del Partido Comunista durante toda su vida (falleció en 2015). Un hijo suyo se vinculó a las FARC, y hoy actúa como comandante del Bloque Oriental de esa organización. 
(algunas integraron la colonia dirigida por Erasmo Valencia y participaron en la sublevación del 9 de abril). Esto dio inicio a una etapa inédita en la lucha política (que se hizo extensiva a toda la región), en donde los comunistas tuvieron un papel especial, al asumir el liderazgo en la resistencia armada. Este proceso, que adquirió la forma de autodefensa y estuvo marcado por el uso de la violencia, permitió la configuración de una generación de dirigentes campesinos que otorgó a la lucha agraria nuevos sentidos, y tuvo en Juan de la Cruz Varela a su más destacado exponente ${ }^{16}$.

Para los años cincuenta, la violencia se desplegó con fuerza en la región de Sumapaz, especialmente en Pandi, Cabrera y Pasca. Durante el gobierno del general Gustavo Rojas Pinilla, el Ejército arreció la persecución a los campesinos e ilegalizó el Partido Comunista (junio de 1954). Como reacción, en Pasca se organizó el Comité Pro-Paz y un Sindicato de Oficios Varios, que jugó un importante papel en las denuncias contra los atropellos cometidos por la dictadura militar. Más adelante vino la amnistía y Juan de la Cruz Varela se acogió a la medida ofrecida por el gobierno, haciendo la respectiva entrega de armas en Cabrera el 31 de octubre de 1953. Sin embargo, la violencia continuó y Sumapaz fue declarado en 1955 como zona de operaciones militares, rompiéndose así lo pactado en 1953, lo que dio origen nuevamente a la resistencia campesina armada.

En julio de 1957, una vez depuesto Rojas Pinilla, Juan de la Cruz Varela, a nombre de la guerrilla del Sumapaz, y el gobierno de la Junta Militar, representado por el ministro de gobierno José María Villarreal y Carlos Holguín, gobernador de Cundinamarca, se reunieron en Pasca y suscribieron un

16 A raíz de la muerte de Erasmo Valencia en julio de 1949, Juan de la Cruz Varela, su discípulo más aventajado, se vinculó al comunismo en 1950, y asumió la vocería de los campesinos de Pasca y el Sumapaz, convirtiéndose en los años posteriores en su principal líder, alcanzando una resonancia nacional. Para el conocimiento de la vida de Juan de la Cruz Varela, se puede consultar los trabajos de Londoño, Juan de la Cruz Varela...; además, Laura Varela Mora y Deyanira Duque Ortiz, Juan de la Cruz Varela, entre la historia y la memoria (Bogotá: Universidad Antonio Nariño, 2011); y Laura Varela Mora y Yuri Romero, Surcando amaneceres. Historia de los agrarios de Sumapaz y Oriente del Tolima (Bogotá: Universidad Antonio Nariño - Alcaldía Local de Sumapaz, 2007). 
acuerdo que apaciguó las viejas tensiones ${ }^{17}$. En 1958 los agrarios se convirtieron en una fuerza política, de la cual resultó electo Varela a la Asamblea de Cundinamarca, expresando un apoyo social que se mantuvo en las elecciones de los años siguientes, como ocurrió en 1960, cuando las listas de los agrarios superaron ampliamente a las del oficialismo, como se observa en la siguiente tabla:

\begin{tabular}{|l|c|c|}
\hline \multicolumn{1}{|c|}{ Municipio } & $\begin{array}{c}\text { Votos del Mov. } \\
\text { Agrario }\end{array}$ & $\begin{array}{c}\text { Votos del } \\
\text { oficialismo }\end{array}$ \\
\hline Pandi y Cabrera & 1.119 & 830 \\
\hline San Bernardo & 192 & 100 \\
\hline Pasca & 1.727 & 144 (direccionistas) \\
\hline Fusagasugá & 2.800 & 400 (direccionistas) \\
\hline
\end{tabular}

Tabla 1. Resultados de las elecciones parlamentarias en 1960 en Sumapaz. Fuente: Laura Varela y Deyanira Duque, Juan de la Cruz Varela, entre la historia y la memoria (Bogotá: Universidad Antonio Nariño, 2010), 268.

En síntesis, la historia de Pasca en la primera mitad del siglo XX, permite identificar el contexto social que sirvió para el surgimiento de liderazgos locales y regionales que se forjaron en medio de las confrontaciones agrarias y políticas entre los años de 1930 y 1958, y sirve para comprender la configuración de una estructura agraria en donde prevaleció la pequeña propiedad, hecho que se asemejó a la aplicación de una reforma agraria ${ }^{18}$. Este recuento permite a su vez, reconocer que, al momento de arribar el padre Hincapié Santamaría a Pasca en 1958, por lo menos dos generaciones de pobladores habían vivido ciclos de luchas alentadas por demandas agrarias, que se expresaron en experiencias organizativas y acciones políticas diversas como la participación electoral y la autodefensa armada. En las contiendas electorales celebradas en ese periodo, el liberalismo y el comunismo recibieron

17 Varela y Duque, Juan de la Cruz Varela, entre..., 83.

18 Santiago Álvarez, Leviatán y sus lobos. Violencia y poder en una comunidad de los Andes colombianos (Buenos Aires: Editorial Antropofagia, 2004), 48. Raúl Herrera, dirigente comunista, concejal de Pasca y diputado en varias oportunidades, refiriéndose a ese periodo, interpreta la distribución de la tierra como producto de acciones con las que «derrotamos el latifundismo y los campesinos adquirieron sus parcelas» (Entrevista a Raúl Herrera, Pasca, 2012). 
apoyos de la población, particularmente desde los años treinta, lo que posibilitó la modificación del mapa político de la localidad: si Pasca al comienzo del siglo XX era un bastión del conservatismo, desde los años treinta $-\mathrm{y}$ salvo en ciertos momentos-, viró hacia el campo de las ideas radicales, en su variante liberal gaitanista o comunista, tendencia que se mantuvo hasta bien entrada la segunda mitad del siglo $\mathrm{XX}^{19}$.

\section{El padre Jaime Hincapié Santamaría}

El padre Hincapié Santamaría nació el 1 de octubre de 1914 en Medellín. Sus padres fueron Leopoldo Hincapié Garcés, médico cirujano educado en París, y Olga Santamaría Herrán, nieta del general Pedro Alcántara Herrán, y bisnieta y ahijada de bautismo del general Tomás Cipriano de Mosquera. En un contexto con una tradición católica fuerte, en donde era deseo de cada familia tener por lo menos a uno de sus miembros como sacerdote o monja ${ }^{20}$, el caso de los Hincapié Santamaría no fue la excepción. A los catorce años, y luego de haber cursado los estudios primarios y secundarios en el Colegio de San José de los Hermanos Lasallistas, Jaime ingresó al Seminario Conciliar de Medellín. "Allí -dice una biógrafa suya-sobresalió por su conocimiento de la Biblia que aprendió muy pronto a leer en hebreo, y en esta lengua la leyó hasta su muerte» ${ }^{21}$.

En 1938 se trasladó a Bogotá para concluir los estudios en el Seminario Mayor. Pudo así Hincapié Santamaría oficiar como capellán del coro de la Catedral y ser ayudante en el Provisariato. El 25 de diciembre de 1938 recibió el sacerdocio,

19 El testimonio de una habitante del municipio es diciente del proceso advertido, aunque la explicación ofrecida no es necesariamente la que esbozamos como tesis: «[...] Pasca ha tenido de todo hace más de 100 años o hasta hace 70, 80 años. Todos los de aquí de Pasca, nuestras familias conservadoras, todos los de aquí, los que somos de aquí, familias conservadoras, empezó a llegar cuando la hegemonía conservadora en Colombia, pues esto era eminentemente conservador, muchos pueblos, pero empezó a llegar gente de Une y esto se liberalizó». Entrevista a María Tránsito Soacha (Directora del MAP desde hace varias décadas), Pasca, 2012.

20 Catalina Reyes, La vida cotidiana en Medellín; 1890-1930 (Medellín: Colcultura, 1996).

21 Olga Cock Hincapié, «In memoriam Jaime Hincapié Santamaría», Boletín de Historia y Antigüedades, nº 833 (2006): 463. 
ofreciendo su primera misa en el Convento del Carmen en Medellín. Al año siguiente, y por orientación de Monseñor Ismael Perdomo, Hincapié Santamaría fue enviado con otros sacerdotes a atender las parroquias de Guataquí, Jerusalén, Nariño, Pulí y Beltrán. Posteriormente, en 1942, acompañó a Monseñor Juan Manuel González para su posesión como Arzobispo de Popayán, la tierra de sus antepasados.

Al poco tiempo, regresó de nuevo a la parroquia de Guataquí, en donde permaneció hasta 1945, cuando, gracias a una beca otorgada por Monseñor Ismael Perdomo, el padre Hincapié se trasladó a Estados Unidos para adelantar estudios de desarrollo rural. En la Universidad Católica de Washington, D.C. y de Antigonish, Nova Scotia, en Canadá, recibió cursos de Servicio Social y Movimiento Cooperativo (junto al Padre Alberto Hurtado, considerado el patrono de los trabajadores en Chile). Al concluir los estudios, el padre Hincapié recorrió Canadá y parte de Estados Unidos, «para hacer observaciones de reforestación, control de erosión, mejoramiento de vivienda y salud $\rangle^{22}$.

En 1951 fue designado como párroco de Anolaima. Allí adelantó labores con los pobladores, perfilándose como un destacado agente cultural ${ }^{23}$. En el campo educativo, por ejemplo, promovió la creación de varios establecimientos. Además, mostró interés por las actividades agrícolas, ayudando

22 Cock, "In memoriam...», 466. Hincapié Santamaría participó en 1946 en el Congreso de Educación Católica y en 1948 en el Congreso de Colegios Católicos en Bolivia. En 1949 monseñor Perdomo lo envió como delegado para el Seminario de Educación de Adultos y Alfabetización, organizado por la Unesco y la OEC en Brasil.

$23 \mathrm{Al}$ indagar por el papel de los curas de pueblo, se observa que suelen ser relegados del análisis científico. Por ejemplo, son pocas las investigaciones que, desde la historia, la sociología o la antropología, analicen el papel ejercido por estas autoridades religiosas en los poblados del país. Recientemente Amanda Caicedo ha dado pistas sugerentes en su estudio sobre los curas de la Diócesis de Popayán en el siglo XVIII, para interpretar a los curas de pueblo como agentes hegemónicos y mediadores culturales, y no como simples correas de transmisión entre las autoridades y los fieles, «que trasladan mandatos de arriba en dirección descendente y con actitudes incuestionables y sí, en cambio, apreciándolos como sujetos activos y cambiantes que se mueven en medio de colectivos e individuos que son también activos y cambiantes». Ver Amanda Caicedo Osorio, Construyendo la hegemonía religiosa. Los curas como agentes hegemónicos y mediadores socioculturales (diócesis de Popayán, siglo XVIII) (Bogotá: Ediciones Uniandes, 2008), xxiii. 
al mejoramiento de la vida de los pequeños propietarios. En el ámbito cultural ${ }^{24}$, el padre Hincapié revivió la Fiesta del Corpus, participando en su organización (que incluía exposición de frutas con figuras de carácter religioso), y que se tomó como una explicación para entender el renacer de las costumbres tradicionales de sus pobladores. Una nota de prensa resaltó en su momento el papel del padre Hincapié en el fortalecimiento de la Fiesta del Corpus:

En la fiesta del Corpus, que hoy celebra el mundo católico, Anolaima tiene puesto todo su fervor y todo su orgullo. El párroco de esa población, Padre Jaime Hincapié Santamaría, ha cumplido una hermosa obra, digna de ser tomada como ejemplo, y ha realizado una tarea educativa y social de altísimo mérito. Especialmente en el terreno agrícola. Cada año organiza, con ocasión del Corpus, una exposición de frutos $^{25}$.

\subsection{El padre Hincapié en Pasca}

La mejor arma del Padre Jaime Hincapié Santa María para atraer a la gente a la iglesia y para que cambiara de mentalidad fue hacer obras ${ }^{26}$.

El padre Hincapié llegó a Pasca el 2 de mayo de 1958, en un momento difícil para el municipio. Recuerda María Tránsito que en el pueblo no había luz y la gente, pesimista, estaba vendiendo sus casas, amedrentados por la violencia política y la estigmatización que sobre los habitantes se registraba ${ }^{27}$.

\footnotetext{
24 Siguiendo a Amanda Caicedo, las actuaciones del Padre Hincapié Santamaría en Anolaima (y posteriormente en Pasca) deben entenderse como recursos que buscan fortalecer la hegemonía católica, acudiendo a diversas estrategias, que varían de acuerdo a las condiciones sociales, culturales y políticas de las parroquias. Por ejemplo, el control sociocultural y la integración cultural, con las que se buscaba introyectar los valores católicos y establecer la convivencia comunitaria en contextos amenazados por conflictos sociales. Un estudio sobre la violencia de los años de 1950 en la región en donde se ubica Anolaima, destaca la labor social del Padre Hincapié, quien «luchó tesoneramente por contener la hecatombe». Ver Germán Guzmán Campos, La violencia en Colombia. Parte descriptiva (Bogotá: Ediciones Progreso, 1968), 131.

25 "Corpus Christi en Anolaima», El Tiempo, Bogotá, 20 de junio de 1957, 6.

26 Cock, «In memoriam...», 468.

27 Soacha, entrevista.
} 
No obstante, al padre Hincapié no le era desconocida esa situación, ya que había estado en contextos parecidos en distintas regiones de Cundinamarca. Pronto, el padre definió una estrategia sociocultural para legitimar su autoridad ante la comunidad. En ese propósito, la educación se convirtió en una prioridad para él, y como era norma en la Iglesia Católica desde los tiempos del Concordato de 1885. Al constatar la existencia de una débil infraestructura educativa en la localidad -había solo un pequeño colegio parroquial de enseñanza primaria-, el padre promovió la construcción de planteles para que los pobladores pudiesen realizar estudios. Con recursos propios, compró un terreno a las Hermanas de La Presentación, donde se construyó la Normal Parroquial, que fue bautizada con el nombre de Nuestra Señora de la Encarnación. Para estimular el ingreso de las personas al plantel, el padre facilitó becas y estableció que no se cobrará pensión a quienes manifestaran su interés en estudiar. Ese mismo año, 1959, solicitó al Ministerio de Educación ayuda para crear una Escuela Hogar para Campesinas, y consiguió que la Gobernación de Cundinamarca comprara la Hacienda El Retiro (propiedad de la familia León Gómez desde el siglo XIX). En una parte del terreno se levantó la granja agrícola y luego, cuando la Normal pasó a manos de la administración departamental y quedó libre el terreno donde funcionaba, por orden del padre Hincapié se demolió el edificio y se construyó un campo de deportes que fue inaugurado el primero de mayo de 1968.

Para la ejecución de estas obras, el padre Hincapié, con notable astucia, buscó el involucramiento de la comunidad, logrando en poco tiempo cambiar la percepción que tenían los pobladores de la Iglesia Católica, a la que veían en muchos casos con desconfianza y como una aliada de los poderosos. En esos términos, pudo verse afectada la legitimidad de que gozaban los líderes agrarios, algo que estos «no se lo perdonaban a él $»^{28}$. En ese cambio de percepción, incidió la forma como

28 Soacha, entrevista. 
actuaba el padre, quien solía evangelizar valiéndose de sus conocimientos culturales: por ejemplo, en las misas hacía referencia a la botánica, asociando el color de las pasifloráceas con la pasión de Cristo; o a la astronomía, para relacionar el solsticio de verano y el solsticio de invierno con la encarnación y nacimiento del Niño Jesús ${ }^{29}$. En la inauguración de las obras solía invitar «a toda la gente para que en realidad creyeran un poco en la iglesia (...), en los curas», y así «cambiarle un poco la imagen a Sumapaz» ${ }^{30}$. Incluso aún se le recuerda, porque al llegar al municipio, «ni cobraba por los matrimonios» ${ }^{31}$.

El padre Hincapié era portador de un marcado discurso anticomunista, como lo dejan ver los testimonios recogidos. Sin embargo, tenía la destreza para desenvolverse en el terreno, valorando las condiciones sociales y políticas que allí afloraban. En ciertas situaciones parecía despertar su intolerancia, por ejemplo, cuando no casaba a parejas de campesinos que eran comunistas, porque «los comunistas eran mala gente» ${ }^{32}$, o simplemente no gustaba de ellos ${ }^{33}$. De cualquier modo, con el paso del tiempo, las circunstancias políticas hicieron que tanto los militantes comunistas como el padre Hincapié, interactuaran, originándose, con el paso del tiempo, a una relación que parece haber estado marcada por el afecto y el respeto.

29 La entrevista a la directora del MAP fue importante porque permitió conocer aspectos de la vida pública del padre Hincapié. María Tránsito interpreta la actuación del padre Hincapié en la lógica amigo - enemigo, bueno - malo, común en contextos de enfrentamiento político, no duda en considerar que el padre Hincapié vio en las obras públicas una forma de disputar a los agrarios, formas de legitimidad política y social.

30 Soacha, entrevista.

31 Un habitante recuerda con gracia que, recién llegado el padre Hincapié, este «ni cobraba por los matrimonios. Decía: Ahí lo que quieran dar». Octavio Torres Ceferino (habitante del municipio), entrevista por José Abelardo Díaz Jaramillo, 2012.

32 Elvia Higuera y Carlos Rey (habitantes de Pasca), entrevista por José Abelardo Díaz Jaramillo, 2012.

33 Raúl Herrera (líder agrario comunista, ex concejal y ex diputado), entrevista por José Abelardo Díaz Jaramillo, 2012. 


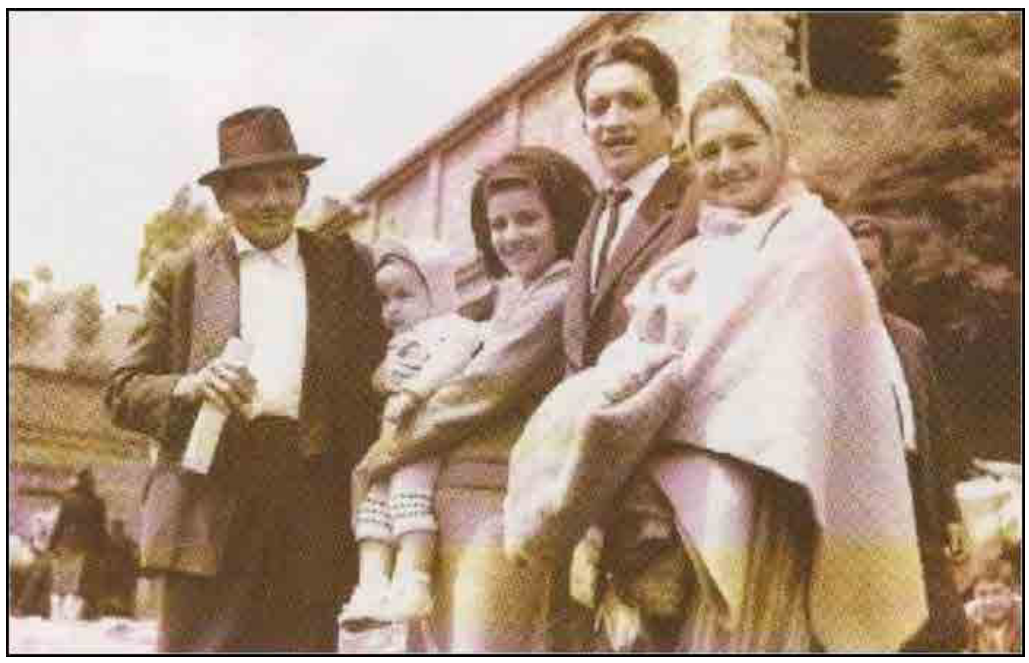

Imagen 1. Juan de la Cruz Varela con su familia en Pasca.

Fuente: Laura Varela y Deyanira Duque, Juan de la Cruz Varela, entre la historia y la memoria (Bogotá: Universidad Antonio Nariño, 2010), 262.

Es evidente, al respecto, que el activo papel del padre Hincapié y el creciente grado de aceptación que recibió, auguraban más temprano que tarde, un encuentro entre él y Juan de la Cruz Varela, el líder más destacado entre los agrarios, quien recogía las aspiraciones de los campesinos de poder vivir labrando la tierra, sin ser perseguidos por el Estado, y sin ser estigmatizados ${ }^{34}$. El primer encuentro entre el padre Hincapié y Juan de la Cruz ocurrió en $1968^{35}$ en la vereda Lázaro Fonte. Desde ese momento comenzó una relación, que al comienzo estuvo marcada por la desconfianza, pero, después, y contra todo pronóstico, viro hacia el respeto.

34 Para los años sesentas, los pobladores de Pasca y de todo Sumapaz, fueron objeto de una estigmatización social, promovida por sectores de la clase política tradicional, siempre proclive a emplear el imaginario anticomunista para legitimar la persecución a sectores de la población colombiana. Ser de Sumapaz (o de Pasca) fue, de hecho, sinónimo de comunista y guerrillero. Ver el estudio de José Jairo González, El estigma de las repúblicas independientes 1955-1965 (Bogotá: CINEP 1992).

35 En 1960 Juan de la Cruz Varela fue elegido como suplente a la Cámara de Representante, en la lista que encabezó Alfonso López Michelsen a nombre del Movimiento Revolucionario Liberal (MRL). Como ya anotó, Varela había sido elegido para la Asamblea Departamental de Cundinamarca, y en otra ocasión fue concejal de Pasca. 
Olga Cock describe el principio de la relación entre Hincapié y Varela en los siguientes términos:

Se enteró el Padre de que el jefe marxista estaba interesado en un libro: Las grandes batallas de la libertad, de Aníbal Galindo. El Padre Jaime Hincapié Santa María no descansó hasta que lo consiguió en una librería de viejo y se lo envió de regalo. Varela escribió al Padre, agradeciéndole y le decía: «Recibo con mucha mansedumbre y respeto su cristiana bendición en el mes de María tanto para mis compañeros, como para este su feligrés que lo respeta y estima $»^{36}$.

Es comprensible que la relación entre un líder comunista y un párroco suscitara en la comunidad expectativas enormes. Como en la novela Don Camilo ${ }^{37}$, del escritor italiano Giovannino Guareschi, se trataba en este caso de dos figuras públicas locales con marcos ideológicos y trayectorias biográficas diferentes, pero respetados y obedecidos por la comunidad. En una investigación sobre la vida de Juan de la Cruz Varela, la actual directora del MAP, María Transito Soacha, afirma que el activismo social que promovió el padre, fue recibido con satisfacción por el líder agrario:

Y nació la amistad (...) y con don Juan se hicieron muy buenos amigos, se veían muy poco pero el padre lo admiraba, el padre le mandaba paquetes de café, le mandaba libros, recuerdo que alguna vez don Juan, en una de las venidas aquí, porque ya cuando él venía acá a Pasca, (...) don Juan venía a saludar al padre, y empezaron así la amistad y el padre lo respetaba mucho, igual don Juan, a pesar de que las ideas de ellos eran diferentes ${ }^{38}$.

Con el paso del tiempo, la amistad se fortaleció. Como lo recuerda Raúl Herrera, el padre Hincapié y Juan de la Cruz Varela "se quisieron mucho», sin que las tensiones desaparecieran entre ellos. De hecho, el padre criticaba continuamente a los comunistas, como lo recuerda Herrera:

36 Cock, «In memoriam...», 471.

37 Giovanni Guareschi, Don Camilo (México D.F.: Editora Latino Americana, S.A., 1957).

38 Varela y Duque, Juan de la Cruz Varela, entre, 112. 
[...] Ah, que esa organización de los comunistas, que esto y lo otro, que si se cuándo; que por qué no las juntas de acción, que era lo que tenía que trabajar con eso; pero bueno, comienza la cuestión de la lucha por la paz y nos fuimos vinculando a él y verracamente se mejoró las relaciones con él. (...) Entonces se fue compartiendo con nosotros, las reuniones en las escuelas, él iba por allá, lo invitábamos, y él estaba con nosotros, nos integrábamos con el padre Hincapié y el jugo un papel muy importante en Pasca, ya dejo la cuestión de regañarnos, de molestarnos de luchar contra nosotros y entonces cambio, dijo: 'no, ustedes tienen la razón hay que echar por defender la paz de la región del Sumapaz y el progreso, estoy con ustedes', nos invitaba a misa, nosotros veníamos a misa ${ }^{39}$.

Lo cierto de todo esto es que el Partido Comunista prestó en esa época una colaboración importante al padre Hincapié ${ }^{40}$.

\section{El Museo Arqueológico de Pasca ${ }^{41}$}

El padre Jaime sentía un especial interés por los conocimientos históricos y científicos. De hecho, formó una biblioteca en las instalaciones del museo, que fue enriqueciendo con el paso de los años, y en la cual, según afirman varias fuentes, reposan documentos originales de la época de la Independencia y del periodo republicano del siglo $\mathrm{XIX}^{42}$. Valga destacar que el interés de los párrocos por el pasado republicano y colonial no fue extraño. Hubo casos, como el del padre José Rafael Poveda, considerado pionero en la formulación de estudios

\footnotetext{
39 Herrera, entrevista.

40 Horacia Rodríguez (Concejal de Pasca), entrevista por José Abelardo Díaz Jaramillo, 2012.

41 De acuerdo con la UNESCO, los museos de arqueología se distinguen porque sus colecciones provienen «en todo o en parte de las excavaciones». En el Directorio de Museos, la categoría Arqueología se subdivide en Arqueología Histórica, Marina y Prehispánica. Ver Ministerio de Cultura y Museo Nacional de Colombia, Directorio de Museos de Colombia (Bogotá: Ministerio de Cultura, 2002), 24. El número de museos en Colombia es impreciso: para 1996 existían 325 y en 2002 la cifra se elevó a 424.

42 El autor no pudo consultar la biblioteca en las visitas que realizó al MAP, por decisión de su directora, con lo cual se hubiese podido identificar el tipo de literatura que logró reunir el padre Hincapié, y de paso cotejar la presencia de libros que guardan alguna relación con la historia del descubrimiento de la Balsa de Oro.
} 
afroamericanos en Colombia ${ }^{43}$; o el del padre Julio Sabogal, autor de una historia de Fusagasugá, en donde se resaltó la importancia del pasado indígena ${ }^{44}$. En fin, los ejemplos son numerosos ${ }^{45}$.

Es probable que las lecturas que realizó el padre, especialmente textos de cronistas de la conquista, lo haya llevado a reconocer la importancia que tuvo Pasca en la época prehispánica ${ }^{46}$. Esa singularidad histórica la pudo corroborar con los descubrimientos de utensilios y objetos que hacían los campesinos de manera regular, de los cuales él supo en sus correrías por las veredas del municipio. De ahí surgió la idea de crear un museo, que en poco tiempo se convirtió en una campaña de recolección de material prehispánico, en donde los campesinos jugarían un papel especial. En 1968 se iniciaron las labores, para lo cual se adecuó una pequeña edificación contigua a la iglesia, en donde se reunieron las primeras piezas (cerámicas, fósiles, piedras pulimentadas, moldes para fundición de oro, joyas y otros utensilios) que los labriegos iban encontrando en la zona rural y entregaban al padre Hincapié.

43 Hernando Andrés Pulido Londoño, «José Rafael Poveda S.J. (1916-1992): el programa de los estudios afroamericanos y los inicios de la reflexión antropológica sobre poblaciones negras en Colombia», Maguaré, n 21 (2007).

44 Julio Sabogal, Fusagasugá: Historia y geografía (Bogotá: Imprenta y Lit. de Juan Cosio, 1919).

45 Por ejemplo, Fray Francisco Romero, quien, a finales del siglo XVII, en su afán de «demostrar que se había internado en territorios en los que subsistían las 'idolatrías' y con ello, obtener fondos financieros para continuar su obra misionera", hizo posible la existencia de «la primera colección preservada proveniente del Nuevo Reino de Granada»; o del padre Romualdo Cuervo, a quien se debe la creación del Museo del Hospicio; o el cura José Domingo Duquesne y su 'calendario muisca'. Al respecto, Clara Isabel Botero, El redescubrimiento del pasado prehispánico de Colombia: viajeros, arqueólogos y coleccionistas, 1820-1945 (Bogotá: Instituto Colombiano de Antropología e Historia, Universidad de los Andes, 2006).

46 Pasca fue, efectivamente, un lugar de importancia en la estructura organizativa del reino muisca, como ha sido resaltado en investigaciones diversas: Jorge Augusto Gamboa Mendoza, El cacicazgo muisca en los años posteriores a la Conquista: del sihipkua al cacique colonial, 1537-1575 (Bogotá: Instituto Colombiano de Antropología e Historia 2010); Carl Henrik Langabaek Rueda, «Informe preliminar sobre tasas de maíz arqueológico encontradas en Pasca, Cundinamarca», Boletín de Arqueología, $\mathrm{n}^{\circ}$ 3, 1987; Luisa Fernanda Herrera, «Excavación arqueológica en Pasca: una zona limítrofe y de posibles contactos Muisca-Panche». (Tesis de Grado, Universidad de los Andes, 1972). 
Como se anotó, el papel de los campesinos en el proyecto fue decisivo: de hecho, uno de los propósitos del padre Hincapié fue vincular a los pobladores en las diversas tareas que la obra demandaba ${ }^{47}$. Aquí surge un interrogante: ¿Por qué un museo de esas características en una localidad como Pasca? Para responder al interrogante es necesario volver al planteamiento central del análisis: el padre Hincapié conjugó sus intereses intelectuales por el pasado, con la pretensión de disputar al movimiento agrarista la autoridad social entre la población, para lo cual pudo haber encontrado en el pasado prehispánico -en su representación material- una oportunidad singular. Reconocer la existencia de un pasado original, autóctono, que reposaba debajo de la tierra, se convertía casi que en una obligación para los campesinos, quienes debían proceder a recuperarlo para ser expuesto en el lugar diseñado para la (su) memoria social: el museo.

Así, la forma de valorar y apropiar un pasado indígena en Pasca, fue condicionado por las tensiones del presente, que, como se advirtió, estaba marcado por conflictos políticos de profunda raigambre. Para tal propósito, el padre Hincapié difundió una especie de mito de origen, que tenía sus comienzos mucho antes de la primera mitad del siglo XX (antes de los conflictos agrarios y el surgimiento de las ideologías radicales), al que podría accederse a través de vestigios materiales que servirían a su vez para promover un sentido de pertenencia, y así poder identificar lo que era propio y ajeno a la comunidad ${ }^{48}$. En esos términos, el museo tendría una doble tarea: narrar el pasado indígena local y educar a los pobladores en el presente.

Algunos testimonios recogidos permiten inferir que ese fue un interés especial del padre Hincapié. De hecho, varias personas entrevistadas (mayores de sesenta años), coinciden en señalar que el padre insistía a los pobladores en la búsqueda de objetos antiguos, con el propósito de que fuesen ubicados en

47 El MAP se inauguró en marzo de 1973. En 1979, con ayuda de la Gobernación de Cundinamarca, amplió sus instalaciones originales («El de Pasca, un museo con sotana", El Tiempo, Bogotá, 23 de mayo de 1994).

48 Rodríguez, entrevista. 
el museo $^{49}$. Para garantizar una vinculación amplia a esa labor, el padre solía aprovechar las misas, ocasión que congregaba a personas procedentes de la zona rural del municipio. Víctor Manuel Cruz Dimate recuerda lo que el padre dijo en alguna oportunidad a los campesinos en una misa: «[...] les recomiendo que donde vayan andando, puay una mucurita, un chorotico, una cosita puay que vean, tráiganmela que yo se la compro». Así, logró reunir «hartas cosas que la gente le llevó, mucuritas, (horoticos $»^{50}$.

Para recompensar a los campesinos que se acercaban a entregar objetos descubiertos, el padre Hincapié les obsequiaba libras de café ${ }^{51}$. Los objetos que más se entregaron eran hachas y ollas en cerámica. Sin embargo, pronto surgió una práctica que ejemplificaba la inconformidad de los labriegos: «lo que más traía la gente era herramientas y herramientas, muy poca cerámica, rara vez le mostraban una cerámica», es decir, «le traían lo que menos valía ${ }^{52}$. Ese comportamiento advertía de tensiones que se originaron por las expectativas que se generaban entre los campesinos en torno a las piezas que descubrían, y que no se traducía en recompensas esperadas ${ }^{53}$. El siguiente testimonio recrea el ambiente que se originó:

Cuando llegaba el sacerdote a esas veredas el sacerdote pues solicitaba esas vajillas y esos platos de barro para hacer... como para cambiar e intercambiar objetos; digamos, yo te doy el plato y te doy comida por ese cambiar, ese intercambio; digamos, le doy café, le doy sal, maíz, y por esos momentos también de escases de alimentos, se veía esa misma connotación de intercambios de alimentos, entonces se podría decir que a la vez que el padre ayudó y fomentó ayuda a sacar al municipio, también formó como un odio

49 Saúl Hortúa (habitante de Pasca), entrevista por José Abelardo Díaz Jaramillo, 2012.

50 Víctor Manuel Cruz Dimate (habitante de Pasca), entrevista por José Abelardo Díaz Jaramillo, 2012.

51 Higuera y Rey, entrevista; Joaquín Hernández (habitante de Pasca), entrevista por José Abelardo Díaz Jaramillo, 2012. Octavio Torres recuerda que en cierta ocasión encontró un tortero de piedra y lo llevó a donde el padre Hincapié, quien, en recompensa, le entregó dos libras de café; entrevista.

52 Soacha, entrevista.

53 Herrera, entrevista. 
hacia las partes rurales porque esos objetos los campesinos los tomaban como algo suyo, pero tampoco lo querían cambiar por objetos alimenticios ${ }^{54}$.

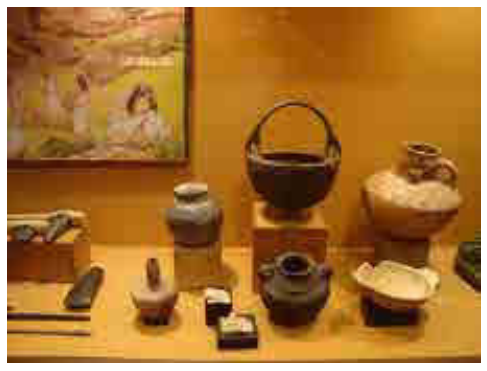

Imagen 2. Objetos que hacen parte de la colección del MAP.

Fuente: «Colección de cerámicas Muiscas», Pasca Cundinamarca blogspot, acceso el 23 de junio de 2013, http://pascacundinamarca.blogspot.com.co/2009/03/8.html

Varios testimonios indican que los militantes agrarios comunistas participaron en distintos momentos de la historia del MAP, desde el levantamiento del edificio hasta la recolección de objetos, y en la gestión de recursos económicos ante instancias gubernamentales para su mejoramiento ${ }^{55}$. Incluso, alentaron a los campesinos a atender el llamado del padre para buscar objetos, acción que concebían como una manera de «educar la gente» ${ }^{56}$.

\subsection{La Balsa de Oro}

"[...] el padre nos dijo una vez en el sermón: No se les olvide: la balsa de oro fue encontrada en el año 1969, en el año que el hombre fue a la luna» ${ }^{57}$.

Sin duda, el acontecimiento más destacado que está ligado a la historia del MAP, es el hallazgo de la Balsa de Oro, una pequeña pieza que representa lo que narraron los cronistas españoles acerca de la ceremonia de El Dorado. Sobre su descubrimiento, ocurrido a principios de 1969, existen distintas versiones. Según

54 Cristian Sánchez Morales (habitante de Pasca), entrevista por José Abelardo Díaz Jaramillo, 2012.

55 Herrera, entrevista; Rodríguez, entrevista.

56 Herrera, entrevista.

57 Torres, entrevista. 
el Banco de la Republica, ese año, «en cercanías de la población de Pasca, al sur de Bogotá, tres campesinos que se encontraban cazando encontraron una vasija de cerámica en cuyo interior estaba una balsa de juncos con las figuras de un cacique y su comitiva ${ }^{58}$. Gabriel Cock Hincapié, sobrino del padre Hincapié señala que un día «llegaron dos campesinos, líderes comunistas, Miguel y Erasmo González, y le preguntaron a mi tío por libros sobre indios y oro. Él les mostró un libro español que hablaba de los muiscas y, al ver allí una balsa en oro, le dijeron que ellos tenían una así, pero con más figuras» ${ }^{59}$. Otra versión recrea el suceso de una manera diferente: «(El padre Hincapié) Hojeaba en su recinto un libro de orfebrería precolombina cuando un humilde campesino señalaba sin titubear una balsa de oro. Es esta, pero más grande, replicaba el labriego Cruz María Dimaté, al señalar la balsa de Siecha que se asemejaba a la que, días atrás, había hallado en compañía de su hijo, en una cueva entre las veredas El Retiro y Lázaro Fonte en Pasca (Cundinamarca) ${ }^{60}$.

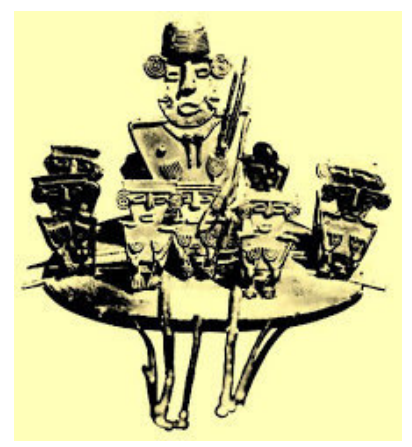

Imagen 3. La Balsa de Siecha que aparece en el libro de Liborio Zerda. Fuente: Liborio Zerda, El Dorado, Bogotá: Biblioteca Popular, 1947, 19.

\footnotetext{
58 «Museo del Oro», Banco de la República, acceso el 18 de julio de 2013, http:// www.banrep.gov.co/museo/esp/inf_2004abril.htm.

59 «Recuerdos de la historia de la balsa de la leyenda El Dorado», El Tiempo, Bogotá, 23 de noviembre de 2011. Existen dos versiones sobre el libro que observaron los campesinos. La primera versión indica que fue el del antropólogo español José Pérez de Barradas, editado por el Banco de la República, el cual contenía una imagen (serigrafía) de la Balsa de Siecha, descubierta en el siglo XIX. La segunda versión señala que se trató de $E l$ Dorado, de Liborio Zerda, publicado en 1883, en donde hay una figura a tempera, que representa la balsa extraída de la Laguna de Siecha en 1856, y que a juicio de Zerda, representa la ceremonia de El Dorado. Liborio Zerda, El Dorado (Bogotá: Biblioteca Popular, 1947), 19.
}

60 «Pasca: una ruta arqueológica», El Tiempo, Bogotá, 2 de marzo de 1996. 
Lo cierto del caso es que, al enterarse el padre Hincapié del descubrimiento de una pieza indígena de esas características, y habiendo conocido la suerte que corrió la Balsa de Siecha ${ }^{61}$, persuadió a los campesinos que habían hecho el descubrimiento para que no la vendieran; mientras tanto, se comunicó con funcionarios del Museo del Oro, para informar del hallazgo con el fin de que hicieran las gestiones de rigor para poder adquirir la pieza. La defensa de la balsa de oro descubierta se convirtió en una obligación para el padre, que no dudó en emplear incluso el púlpito, para resaltar su importancia y el deber de preservarla. De tal modo, y con justa razón, al padre Santamaría se debe que no se hubiese perdido la pieza, como pudo haber ocurrido sin duda alguna, si esta hubiese caído en manos de coleccionistas privados, o destruida para fundir el oro. Finalmente, los campesinos Dimaté recibieron una suma de dinero de funcionarios del Banco de la República, con lo cual se oficializó la adquisición de la pieza por parte del Estado, que la puso a disposición del Museo del Oro $^{62}$.

En Pasca, el descubrimiento de la balsa muisca tuvo efectos notables: por un lado, estimuló en los campesinos el interés por encontrar objetos similares (pensaban esta vez no en las libras de café, sino en dinero) y, por otro lado, reforzó en el imaginario local la imagen que el padre Hincapié había pretendido difundir entre los pobladores, sobre la importancia de Pasca en tiempos anteriores a la llegada de los españoles.

61 La historia de la Balsa de Oro se conocía desde un siglo antes, cuando fue hallada en la Laguna de Siecha en 1856, y fue dada a conocer en 1883 por Liborio Zerda, quien publicó un grabado de la ofrenda de Siecha. Desde entonces se interpretó como una representación de la ceremonia descrita para la Laguna de Guatavita.

62 «Valiosa pieza para Museo del Oro», El Tiempo, Bogotá, 30 de abril de 1969, 1 y 2. La pieza fue puesta en exhibición pública el 29 de abril de 1969. 


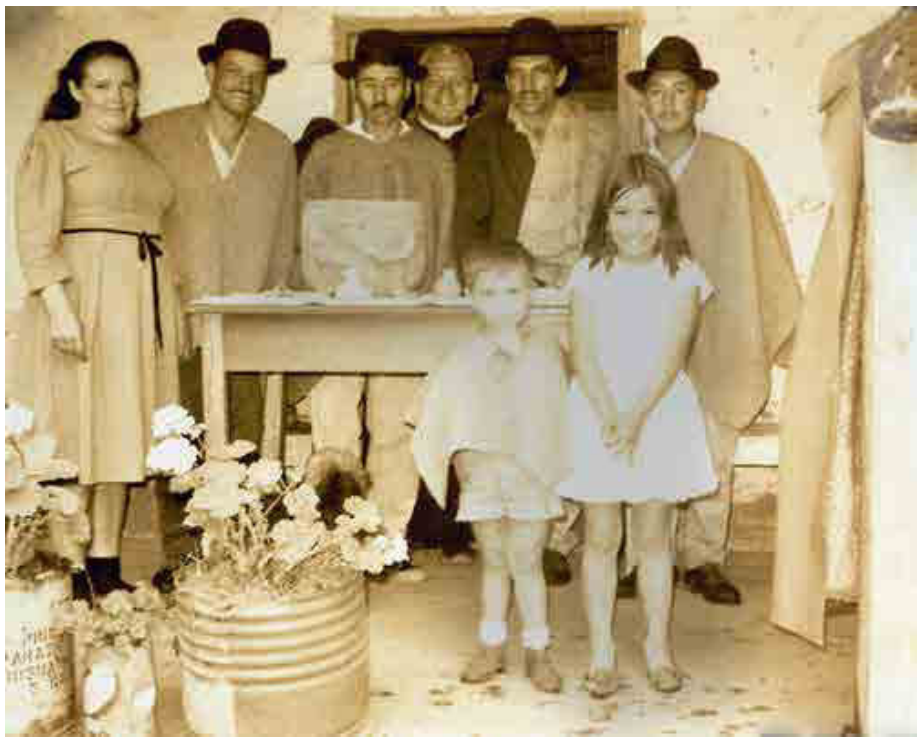

Imagen 4. Cruz María Dimaté, tercero de izquierda a derecha, con su familia. En el centro, en segundo plano, el padre Jaime. Sobre la mesa, la balsa y otros objetos encontrados por los campesinos.

Fuente: «Pasca (Cundinamarca): una balsa, un museo y una cueva», Banco de la República, acceso el 13 de junio de 2013, http://www.banrepcultural.org/blog/ noticias-del-museo-del-oro/pasca-cundinamarca-un-museo-y-una-cueva

\section{Conclusión}

En la reconstrucción de la historia del MAP, sobresalen dos hechos que perfilan el análisis sobre los impactos políticos y culturales que pudo generar la construcción de una edificación de ese tipo en los pobladores de Pasca. Como se argumentó, el MAP respondió a una estrategia sociocultural promovida por el padre Jaime Hincapié Santamaría ${ }^{63}$, en su interés de fortalecer la hegemonía católica entre los pasqueños, principalmente de las áreas rurales, y debilitar la influencia de los líderes agrarios comunistas. Conocedor de la historia del territorio nacional, el padre Hincapié se valió del papel que tuvo el lugar donde se asentaba su parroquia desde la época prehispánica, y que se expresaba en la existencia de vestigios

63 El padre Jaime Hincapié ejerció funciones como párroco de Pasca hasta 1985. Falleció en Bogotá el 1 de abril de 2005. Un reconocimiento a su papel en la creación del MAP apareció en el programa El Minuto de Dios, del 3 de octubre de 2016. Puede verse en el siguiente link: https://www.youtube.com/watch?v=h5FcbBbaVtM 
orfebres, para motivar a los campesinos a emprender labores de búsqueda y entregarlos al naciente museo. Ese ejercicio de recuperación de piezas indígenas iba acompañado de la difusión de una narrativa - débil, por cierto- que resaltaba la importancia de Pasca desde los tiempos prehispánicos, en un interés por promover entre los habitantes un referente identitario que sentaba sus bases en un periodo anterior al de las luchas agrarias que se registraron en la primera mitad del siglo XX.

Una pregunta surge de lo anterior: ¿el MAP generó entre los pobladores del municipio una identidad colectiva que provenía de un pasado indígena local? Las fuentes consultadas indican que no fue así. De hecho, pocos de los pobladores entrevistados asoció el museo a un pasado indígena en el territorio, pero sí a la memoria del padre Hincapié Santamaría, lo cual demuestra el impacto de su figura como líder entre la comunidad. Un argumento que corrobora la ineficacia del museo como posibilitador de un referente identitario ligado a un pasado indígena, es advertido en un estudio antropológico sobre los habitantes de Pasca, en donde se establece que allí nadie "se identifica a sí mismo o es identificado como indígena ${ }^{64}$.

De cualquier modo, es innegable que el MAP promovió referentes identitarios de otro calado entre los pobladores. Nuevamente, los testimonios de los entrevistados son valiosos, porque permiten establecer que el museo sirvió para promover una identidad local que se alimentó de lecturas diversas ${ }^{65}$. Por ejemplo, líderes comunistas como Raúl Herrera, elaboraron una interpretación del significado del MAP, que, a su juicio, les impone el deber de protegerlo. Al respecto, Herrera considera que las piezas del museo representan al «campesino trabajando con la tierra, produciendo la tierra», quienes, en esas labores, «encontraban las cosas que enterraban por ahí los indígenas». El descubrimiento de las piezas produjo una «identidad íntima de los campesinos con el mismo museo», señala el dirigente.

64 Álvarez, Leviatán y sus lobos..., 35.

65 Inés Ardila de Contreras (habitante de Pasca) entrevista de José Abelardo Díaz Jaramillo, 2012. 
Además, el MAP es valioso porque «nuestros indígenas, tuvieron muchas dificultades, los persiguieron, los sacaron de aquí y dejaron toda una historia y en eso hay mucha cuestión por aquí de los indígenas, hay que recoger eso y entregárselo al museo porque es patrimonio de Pasca» ${ }^{66}$.

Este tipo de interpretación, articulada a una ideológica política, es de suma importancia para comprender la historia del MAP. La participación de los comunistas en la iniciativa del padre Hincapié, expresó las posibilidades que podían tener las empresas sociales promovidas por los párrocos en lugares con características socioculturales como las de Pasca. Como se destacó, las relaciones que existieron entre los comunistas y el padre Hincapié fueron difíciles en un comienzo, pero luego tomaron el camino del respeto y la colaboración mutua. La percepción que expresa el líder comunista local sobre el sentido simbólico del MAP, puede explicar por qué en las tomas armadas que realizó las FARC a Pasca en los años noventa del siglo XX, este grupo guerrillero nunca afectó la edificación del museo, ubicada a pocos metros de la plaza principal. Como destaca María Tránsito Soacha, en los ataques armados, los guerrilleros siempre respetaron la edificación, a tal punto que «ni siquiera un grafiti» fue colocado en sus paredes ${ }^{67}$. Que haya sucedido así, podría ser un indicador del peso simbólico que se otorgaba al MAP, convertido en un lugar de memoria que debía ser protegido, incluso en tiempos de guerra.

\section{Fuentes documentales}

\section{Prensa}

"Corpus Christi en Anolaima». El Tiempo, Bogotá, 20 de junio de 1957.

«El de Pasca, un museo con Sotana». El Tiempo, Bogotá, 23 de mayo de 1994.

66 Herrera, entrevista.

67 Soacha, entrevista. 
«Pasca: una ruta arqueológica». El Tiempo, Bogotá, 2 de marzo de 1996.

«Recuerdos de la historia de la balsa de la leyenda El Dorado». $E l$ Tiempo, Bogotá, 23 de noviembre de 2011.

«Valiosa pieza para Museo del Oro». El Tiempo, Bogotá, 30 de abril de 1969.

\section{Entrevistas}

Ardila de Contreras, Inés. Entrevista de José Abelardo Díaz Jaramillo, 2012.

Cárdenas, Álvaro. Entrevista por José Abelardo Díaz Jaramillo. Mayo de 2011.

Cruz Dimate, Víctor Manuel. Entrevista por José Abelardo Díaz Jaramillo, 2012.

Hernández, Joaquín. Entrevista por José Abelardo Díaz Jaramillo, 2012.

Herrera, Raúl. Entrevista por José Abelardo Díaz Jaramillo, 2012.

Higuera, Elvia.; y Carlos Rey. Entrevista por José Abelardo Díaz Jaramillo, 2012.

Hortúa, Saúl. Entrevista por José Abelardo Díaz Jaramillo, 2012.

Rodríguez, Horacia. Entrevista por José Abelardo Díaz Jaramillo, 2012.

Sánchez Morales, Cristian. Entrevista por José Abelardo Díaz Jaramillo, 2012.

Soacha, María Tránsito. Entrevista por José Abelardo Díaz Jaramillo. 2012.

Torres Ceferino, Octavio. Entrevista por José Abelardo Díaz Jaramillo, 2012. 


\section{Bibliografía}

Álvarez, Santiago. Leviatán y sus lobos. Violencia y poder en una comunidad de los Andes colombianos. Buenos Aires: Editorial Antropofagia, 2004.

Banco de la República. «Museo del Oro». Acceso el 18 de julio de 2013, http://www.banrep.gov.co/museo/esp/inf_2004abril.htm.

Banco de la República. «Pasca (Cundinamarca): una balsa, un museo y una cueva». Acceso el 13 de junio de 2013, http:// www.banrepcultural.org/blog/noticias-del-museo-del-oro/ pasca-cundinamarca-un-museo-y-una-cueva.

Botero, Clara Isabel. El redescubrimiento del pasado prehispánico de Colombia: viajeros, arqueólogos y coleccionistas, 18201945. Bogotá: ICANH-Universidad de Los Andes, 2007.

Caicedo Osorio, Amanda. Construyendo la hegemonía religiosa. Los curas como agentes hegemónicos y mediadores socioculturales (diócesis de Popayán, siglo XVIII). Bogotá: Ediciones Uniandes, 2008.

Cock Hincapié, Olga. «In memoriam Jaime Hincapié Santa María». Boletín de Historia y Antigüedades 93, nº 833, (2006): 463-472.

Gamboa Mendoza, Jorge Augusto. El cacicazgo muisca en los años posteriores a la Conquista: del sihipkua al cacique colonial, 1537-1575. Bogotá: Instituto Colombiano de Antropología e Historia, 2010.

Gnecco, Cristóbal. «Observaciones sobre arqueología, objetos y museos». En La arqueología, la etnografía, la historia y el arte en el Museo. Bogotá: Ministerio de Cultura - Museo Nacional de Colombia, 2010.

González, Gerardo. En busca del horizonte. Bogotá: Alekos Publicaciones, 1996.

González, José Jairo. El estigma de las repúblicas independientes 1955-1965. Bogotá: CINEP, 1992. 
Guareschi, Giovanni. Don Camilo. México, D.F.: Editora Latino Americana, S.A., 1957.

Guzmán Campos, Germán. La violencia en Colombia. Parte descriptiva. Bogotá: Ediciones Progreso, 1968.

Herrera, Luisa Fernanda. «Excavación arqueológica en Pasca: una zona limítrofe y de posibles contactos Muisca - Panche». Tesis de pregrado, Universidad de los Andes, 1972.

Langebaek Rueda, Carl Henrik. «Informe preliminar sobre tasas de maíz arqueológico encontradas en Pasca, Cundinamarca». Boletín de Arqueología, $\mathrm{n}^{\circ}$ 3, 1987.

Langebaek Rueda, Carl Henrik. «Patrimonio arqueológico e investigación en el nuevo Museo Nacional de Colombia». En La arqueología, la etnografía, la historia y el arte en el Museo. Bogotá: Ministerio de Cultura - Museo Nacional de Colombia, 2011.

Legrand, Catherine. Colonización y protesta campesina en Colombia 1850-1950. Bogotá: Universidad Nacional de Colombia, 1988.

Londoño, Rocío. Juan de la Cruz Varela. Sociedad y política en la región de Sumapaz (1902-1984). Bogotá: Universidad Nacional de Colombia, 2011.

Marulanda, Elsy. Colonización y conflicto. Las lecciones del Sumapaz. Bogotá: Tercer Mundo Editores - IEPRI, 1981.

Ministerio de Cultura y Museo Nacional de Colombia, Directorio de Museos de Colombia. Bogotá: Ministerio de Cultura, 2002.

Palacios, Marco. El café en Colombia (1850-1970): una historia económica, social y política. México: Fondo de Cultura Económica, 2009.

Pasca Cundinamarca blogspot. «Colección de cerámicas Muiscas». Acceso el 23 de junio de 2013, http://pascacundinamarca. blogspot.com.co/2009/03/8.html.

Pulido Londoño, Hernando Andrés. «José Rafael Poveda S.J. (19161992): el programa de los estudios afroamericanos y los inicios 
de la reflexión antropológica sobre poblaciones negras en Colombia». Maguaré, nº 21 (2007): 89-110.

Reyes, Catalina. La vida cotidiana en Medellín; 1890-1930. Medellín: Colcultura, 1996.

Robinson, J. Cordell. El movimiento gaitanista en Colombia 19301948. Bogotá: Ediciones Tercer Mundo, 1976.

Sabogal S., Julio. Fusagasugá. Historia y geografía. Bogotá: Imprenta y Lit. de Juan Cosio, 1919.

Uricoechea, Ezequiel. Memoria sobre las antigüedades neogranadinas. Bogotá: Biblioteca Banco Popular, 1971.

Varela Mora, Laura.; y Deyanira Duque Ortiz. Juan de la Cruz Varela, entre la historia y la memoria. Bogotá: Universidad Antonio Nariño, Alcaldía Local de Sumapaz, 2011.

Varela Mora, Laura.; y Yuri Romero. Surcando amaneceres. Historia de los agrarios de Sumapaz y Oriente del Tolima. Bogotá: Universidad Antonio Nariño, Alcaldía Local de Sumapaz, 2007.

Vega Cantor, Renán. Gente muy rebelde. Indígenas, campesinos y protestas agrarias. Bogotá: Pensamiento Crítico, 2002.

Velandia, Roberto. Enciclopedia histórica de Cundinamarca. Bogotá: Biblioteca de Autores Cundinamarqueses, 1979.

Zerda, Liborio. El Dorado. Bogotá: Biblioteca Popular, 1947.

\section{Citar este artículo:}

Díaz Jaramillo, José Abelardo. «El museo arqueológico de Pasca: una hipótesis sobre su origen». Historia Y MEMORIA, $\mathrm{n}^{\circ} 15$ (2017): 17-48. DOI: https://doi.org/10.19053/20275137. $\mathrm{n} 15.2017 .5511$ 